\title{
Relationship between pulmonary function and indoor air pollution from coal combustion among adult residents in an inner-city area of southwest China
}

\author{
Y. Jie ${ }^{1}$, H. Houjin ${ }^{1}$, M. Xun ${ }^{2}$, L. Kebin ${ }^{1}$, Y. Xuesong ${ }^{1}$ and X. Jie ${ }^{1}$ \\ ${ }^{1}$ School of Public Health, Zunyi Medical University, Zunyi, Guizhou, China \\ ${ }^{2}$ Department of Medicine Laboratory, Affiliated Hospital of Zunyi Medical University, Zunyi, China
}

\begin{abstract}
Few studies evaluate the amount of particulate matter less than $2.5 \mathrm{~mm}$ in diameter $\left(\mathrm{PM}_{2.5}\right)$ in relation to a change in lung function among adults in a population. The aim of this study was to assess the association of coal as a domestic energy source to pulmonary function in an adult population in inner-city areas of Zunyi city in China where coal use is common. In a crosssectional study of 104 households, pulmonary function measurements were assessed and compared in 110 coal users and 121 non-coal users ( $\geq 18$ years old) who were all nonsmokers. Several sociodemographic factors were assessed by questionnaire, and ventilatory function measurements including forced vital capacity (FVC), forced expiratory volume in $1 \mathrm{~s}$ $\left(F E V_{1}\right)$, the $F E V_{1} / F V C$ ratio, and peak expiratory flow rate (PEFR) were compared between the 2 groups. The amount of $P M_{2.5}$ was also measured in all residences. There was a significant increase in the relative concentration of $\mathrm{PM}_{2.5}$ in the indoor kitchens and living rooms of the coal-exposed group compared to the non-coal-exposed group. In multivariate analysis, current

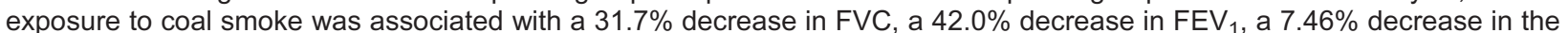
$\mathrm{FEV}_{1} / \mathrm{FVC}$ ratio, and a $23.1 \%$ decrease in PEFR in adult residents. The slope of lung function decrease for Chinese adults is approximately a 2-L decrease in FVC, a 3-L decrease in $\mathrm{FEV}_{1}$, and an $8 \mathrm{~L} / \mathrm{s}$ decrease in PEFR per count per minute of $\mathrm{PM} \mathrm{M}_{2.5}$ exposure. These results demonstrate the harmful effects of indoor air pollution from coal smoke on the lung function of adult residents and emphasize the need for public health efforts to decrease exposure to coal smoke.
\end{abstract}

Key words: Indoor air pollution; Coal combustion; Lung function; Particulate matter

\section{Introduction}

Indoor air pollution (IAP) is the second largest environmental contributor to morbidity worldwide, surpassed only by unsafe water and sanitation $(1,2)$. Exposure to IAP from the combustion of coal and biomass fuels is a significant public health hazard, predominantly affecting poor rural and urban communities in developing countries. Such fuel is the domestic energy source for almost three billion people $(3,4)$, and the resulting smoke strongly contributes to the global burden of mortality, accounting for about 1.6 million of the 59 million deaths annually (5).

Stoves fueled by coal can release 50 times more respiratory irritants during cooking compared to gas stoves, and this leads to high concentrations of air pollutants including carbon monoxide (CO), nitrogen oxide, sulfur dioxide $\left(\mathrm{SO}_{2}\right)$, polycyclic aromatic hydrocarbons, and inhalable particulate matter of different sizes
(6), as well as hazardous accessory elements such as As, $\mathrm{Cd}, \mathrm{Co}$, and others (7). Although most Chinese cities have plans to eliminate coal use in households, many urban communities continue to rely on coal. In Chinese households that use high-sulfur and high-ash coal (low-rank coal) in stoves with limited ventilation, coal burning for cooking or heating substantially contributes to indoor particulate matter levels (8). Small particulate matter less than $2.5 \mathrm{~mm}$ in diameter $\left(\mathrm{PM}_{2.5}\right)$ has been increasingly related to respiratory and cardiovascular morbidity and mortality $(9,10)$. The adult population, particularly women and the elderly, is particularly vulnerable to these adverse health effects because of their greater exposure to IAP from cooking or heating.

Zunyi city possesses abundant coal reserves, is the city most seriously polluted by acid rain, and has record 
high levels of air pollution in China (Figure 1). In the innercity areas of Zunyi, biomass fuels have been widely replaced at home by cleaner energy sources, such as kerosene, liquid petroleum, gas, or electricity, but coal is still a major source of fuel for cooking and heating throughout the year, particularly in the winter. These conditions prompted us to investigate the impact of coal use on pulmonary function among adult residents in an inner-city area of Zunyi. The objective of this study was to assess the relationship between pulmonary function changes in the adult population and IAP from coal use in inner-city areas of Zunyi city, Guizhou province, in southwest China.

\section{Material and Methods}

\section{Study site}

This study was conducted in Zunyi, the largest city in the north of Guizhou province, southwest China. There are 11 inner-city areas in Zunyi: Laocheng (LC) Road, Wangli (WL) Road, Zhonghua ( $\mathrm{ZH})$ Road, Nanmenguan (NMG) Road, Yanan (YA) Road, Zhoushuiqiao (ZSQ) Road, Zhongshan (ZS) Road, Beijing (BJ) Road, Shanghai (SH) Road, Xima (XM) Road, and Dalian (DL) Road, covering a wide range of geographic areas in Zunyi city $\left(105 \mathrm{~km}^{2}\right)$ and a total population of more than 110 million. These 11 inner-city areas are homogeneous in terms of lifestyle, education, employment and income, housing, geographical origin of the residents, and effects of air pollution (11).

Zunyi is a traditional industrial city and is the most seriously polluted by acid rain in China (12). The frequency of acid precipitation in Zunyi was above $80 \%$, and the lowest $\mathrm{pH}$ value of acid precipitation ever reached was 3.2, which was attributed to excessive coal consumption by local industries and households (13). Coal is the major source of fuel for cooking, baking, and heating in the local households during the winter (14). Cooking is mainly done either indoors, with an open-fire traditional cooking stove in a small kitchen without effective ventilation, or in an open or closed kitchen adjacent to the living room within the house.

\section{Study population and selection process}

The study population was selected by a simple random sampling technique. At the first stage of sampling, because of the relative socioeconomic homogeneity among the 11 inner-city areas, one inner-city area, YA Road, was selected by simple random sampling. At the second stage of sampling, because YA Road included 11 residence communities (the communities of Yanan Road Crossing, Juquange, Leitaishan, Shongtao Road, Jiaochangba, Jinyinxincun, Jinshishan, Jueshilandao, Zhenzhu Road, Jinjiang, and Jiancai Road), two residence communities (cluster units), Jiaochangba and Jinshishan, were randomly selected for investigation using the same sampling technique. At the final stage of sampling, households were selected at random using quota sampling. In each selected residence community, the cooking fuel source was identified for each of the households visited, and the interviewer used quota sampling to identify 2 cooking categories that contained 52 households each. The two categories were coal and non-coal (modern energy source) use. The first family was selected by simple random sampling of the residential address number. All adult family members present at the residence who met the inclusion criteria were selected. After that, neighbors living in a residence next door who met the inclusion criteria were recruited and interviewed. If no one was at home, the interviewer returned up to three times before moving to another family next door. If the selected family refused to participate or could not be found, neighbors living in the next residence who met the inclusion criteria were recruited. This procedure was repeated for every house among the selected houses until the targeted number of participants was recruited. The residents were asked to complete the consent form and questionnaire at home.

In the coal-users group, adult residents usually spent their time indoors, especially throughout the winter. The

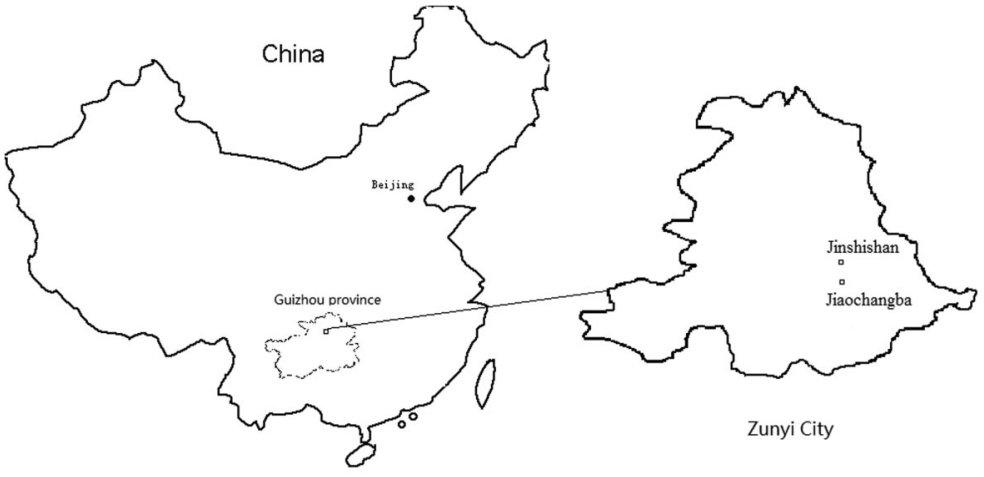

Figure 1. Map of the selected area (Zunyi city) in Guizhou province, China. 
participants of the comparison group not using coal were selected by simple random sampling from the people using modern energy sources. Only nonsmokers identified by questionnaire were included in this study in YA Road, in the city of Zunyi. All respiratory measurements were performed during the winter (from October 2011 to March 2012).

Inclusion criteria for the community studied were 1) no factories or plants within the selected community and 2) eligible residents must be 18 years and older (men and women) and have lived within YA Road in Zunyi city for more than 3 years.

\section{Measurement of pulmonary function}

Lung function was examined by measuring forced vital capacity (FVC), forced expiratory volume in $1 \mathrm{~s}\left(\mathrm{FEV}_{1}\right)$, $F E V_{1} / F V C$, and peak expiratory flow rate (PEFR), according to standard guidelines (15) using a portable electronic FGC-A + spirometer (Anhui Institute of Electronic Science, China). The participants were asked to sit in an upright position with both feet flat on the ground. They were instructed to inhale completely, place the meter in their mouth, and to exhale with maximal force as soon as their lips were sealed around the mouthpiece, while maintaining an upright position. An investigator demonstrated the maneuver. Based on guidelines of the American Thoracic Society (16), maneuvers were only accepted if they had low back-extrapolated volume $(<5 \%$ of the FVC and $<0.15 \mathrm{~L}$ ), both the FVC and $\mathrm{FEV}_{1}$ were within $0.20 \mathrm{~L}$ of the best effort FVC and $F E V_{1}$, and there was a low volume accumulated at the end of the effort. Each subject was tested on three expiratory maneuvers. Data analysis was conducted on the largest FVC of the two curves, the largest $F E V_{1}$, the ratio of the largest $F E V_{1}$ to the largest FVC, and the largest PEFR.

\section{Measurement of pollutants}

During cooking, air pollutant concentrations of particulate matter with an aerodynamic diameter less than $2.5 \mathrm{~mm}\left(\mathrm{PM}_{2.5}\right)$ were measured. During cooking with coal and non-coal fuels in the selected households, indoor concentrations of air pollutant were monitored in the kitchen and living room while outdoor concentrations were also measured. All air sampling was carried out at a height of $1.2-1.5 \mathrm{~m}$ from the floor of each household. Three measurements were obtained from 3 sampling sites at a distance of $1 \mathrm{~m}$ from the center of the cooking stove inside the kitchen. Three measurements were obtained from 3 random sampling sites inside the living room at least $3 \mathrm{~m}$ from the kitchen. Three outdoor measurements were obtained as environmental control samples from 3 random sampling sites outside the study household at least $20 \mathrm{~m}$ from the household.

To measure $\mathrm{PM}_{2.5}$ concentrations inside and outside the households, we used a digital dust monitor (LD-3K; Sibata Scientific Technology Inc., Japan; Figure 2), which is a portable monitor based on the light-scattering principle, with a laser diode as the light source. The monitor determines the relative concentration of $\mathrm{PM}_{2.5}$ by measuring the intensity of the laser beam scattered by particles. The advantage of measuring $\mathrm{PM}_{2.5}$ relative concentration with the LD-3K fine dust monitor was that it allowed an analysis of concentration level (high or low), namely, a relative comparison (screening) and an analysis of variation with time (17). The relative concentration is reported as counts per minute (cpm). To determine the $\mathrm{cpm}$, the following equation was used: $\mathrm{cpm}=$ count value/measuring time (in min). Each measurement was maintained for over $1 \mathrm{~min}$, and three readings were taken for each measurement to calculate the mean relative concentration. There was an interval period of $1 \mathrm{~min}$ between the 3 measurements of $\mathrm{PM}_{2.5}$ in the kitchen, living room, or outdoors, whereas the interval period for measurements between the kitchen, living room, and outdoors was $5 \mathrm{~min}$ in each house.

\section{Data analysis}

Data analysis was carried out using the Statistical Package for Social Sciences version 15.0 (SPSS Inc., USA). Pearson's chi-square tests were used to compare categorical characteristics such as gender, respiratory tract infections, and environmental tobacco smoke exposure (defined by the presence of a smoker in the household) in the two groups. Student $t$-tests were used to compare differences in baseline characteristics (age, height, weight, number of rooms, and number of persons in the household) and pulmonary function indices, as well as indoor and outdoor $\mathrm{PM}_{2.5}$ relative concentrations between cooking fuel categories for adult participants. Multivariate linear regression analysis was used to assess the association between coal combustion and pulmonary function with other sociodemographic factors (e.g., age, gender, height, and exposure to tobacco smoke, etc.) as variable controls. A value of $\mathrm{P}<0.05$ was considered to be significant for all analyses.

\section{Results}

Among the 104 households in the study, we collected data from a total of 231 adult individuals (of 254 available participants); based on their energy source, 110 participants were placed in the coal-exposed group, and 121 participants were selected as the control group. All participants performed acceptable spirometry measurements. $\mathrm{PM}_{2.5}$ relative concentration during cooking was measured in 52 households in the coal-exposed group and 52 households in the unexposed group. The individuals in the coal-exposed and unexposed groups were similar regarding demographic characteristics: $64.5 \%$ were female (exposed) vs $57.9 \%$ (unexposed), with age ranges of 20 to 74 (exposed) and 19 to 71 years (unexposed); the mean heights were $163.7 \pm 6.6 \mathrm{~cm}$ for coal-exposed individuals 


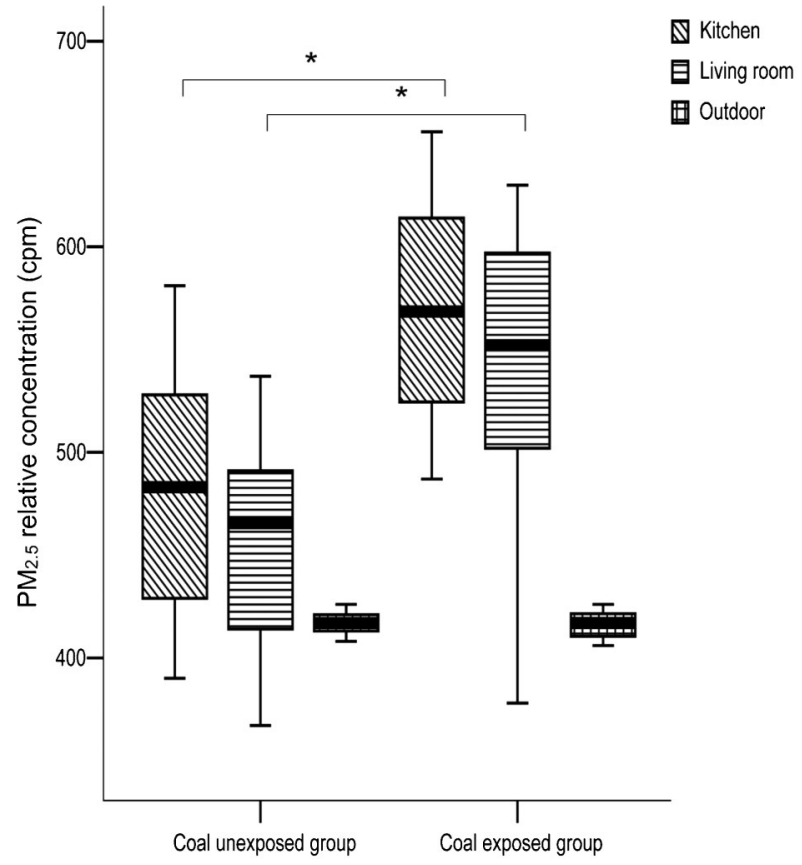

Figure 2. $\mathrm{PM}_{2.5}$ relative concentration according to coal exposed and unexposed groups. ${ }^{*} \mathrm{P}<0.05, t$-test.

and $164.8 \pm 6.8 \mathrm{~cm}$ for unexposed individuals; and the mean weights were $61.1 \pm 7.1 \mathrm{~kg}$ and $62.6 \pm 7.5 \mathrm{~kg}$ for coal-exposed and unexposed individuals, respectively. There was an indication of an imbalance in the two groups regarding the number of persons living in the home $(P=0.053)$. Significant differences were present for the number of rooms in the home $(\mathrm{P}<0.05)$ and for individuals who had recurrent pulmonary tract infections $(30.9 \%$ in exposed vs $13.2 \%$ in unexposed groups, Table 1).

For all pulmonary function test parameters (FVC, $\mathrm{FEV}_{1}, \mathrm{FEV}_{1} / \mathrm{FVC}$, and PEFR), highly significant differences $(P<0.0001)$ were observed between coal-exposed and unexposed individuals, with mean values lower in those exposed to coal (Table 1). The indoor and outdoor $\mathrm{PM}_{2.5}$ relative concentrations during the cooking period in the coal-exposed and unexposed groups were $569.5 \pm 50.1$ vs $477.0 \pm 58.5 \mathrm{cpm}$ (kitchen), $543.2 \pm 65.0$ vs $452.7 \pm 51.2 \mathrm{cpm}$ (living room), and $416.2 \pm 5.9$ vs $417.0 \pm 5.1 \mathrm{cpm}$ (outdoors), respectively. Values of $\mathrm{PM}_{2.5}$ for each group are shown in Figure 2. When the indoor and outdoor concentrations of gaseous pollutant in coalexposed and unexposed groups were compared, the relative concentrations of $\mathrm{PM}_{2.5}$ in the kitchen and living room during coal combustion were significantly higher than during non-coal combustion $(P<0.0001)$, but this was not the case for outdoor concentrations. During coal combustion, the relative concentration of $\mathrm{PM}_{2.5}$ in the kitchen was also significantly higher than in the living room and outdoors $(P<0.0001)$.
Linear regression analysis was used for describing the relationship between coal use and pulmonary function measurements while controlling for the other relevant factors associated with pulmonary function. In regression models adjusted for gender, age, weight, height, number of persons living in a home, number of rooms in a home, history of recurrent respiratory tract infections, environmental tobacco smoke exposure, and $\mathrm{PM}_{2.5}$ relative concentrations in the kitchen, living room, and outdoors (Tables 2-4), current exposure to coal smoke was associated with a $31.7 \%$ decrease in FVC, a $42.0 \%$ decrease in $\mathrm{FEV}_{1}$, a $7.46 \%$ decrease in $\mathrm{FEV}_{1} / \mathrm{FVC}$, and a $23.1 \%$ decrease in PEFR. In the multivariate models, we found that $\mathrm{PM}_{2.5}$ relative concentrations in the kitchen showed a significant effect on FVC, FEV 1 , and PEFR. The dose-response relationship between the $\mathrm{PM}_{2.5}$ relative concentration in the kitchen and lung function changes is shown in Tables 2, 3, and 5. Our models indicate that there was a $2-L$ decrease in FVC and a $3-L$ decrease in $\mathrm{FEV}_{1}$, as well as an $8 \mathrm{~L} / \mathrm{s}$ decrease in PEFR per $1 \mathrm{cpm}$ $\mathrm{PM}_{2.5}$ exposure among adult participants.

\section{Discussion}

In the present study, we performed the first simultaneous evaluation of pulmonary function changes and exposure magnitude in an adult population exposed to coal combustion in China. Our main finding was impaired pulmonary function in both adult males and females who used coal compared to non-users. We also observed a significantly negative association of indoor $\mathrm{PM}_{2.5}$ relative concentration from coal combustion with individual lung function. Coal users had comparatively lower pulmonary function values than non-users. The pulmonary function parameters affected by coal use were FVC, FEV $1, F E_{1}$ / FVC, and PEFR. These findings are thought to be related to decreased airflow both in large and small airways (18). This study also demonstrated some deterioration of pulmonary function in the male subjects who came from coal-using families. Coal use is an important factor in pulmonary function deterioration. The mechanism for decreased pulmonary function and impaired pulmonary health among adult individuals exposed to coal combustion is not clear. Coal smoke is thought to facilitate damaging oxidation reactions in the respiratory tract, especially in the lower airways, as well as pulmonary and systemic inflammatory responses, which may account for many of the toxic responses in exposed individuals $(19,20)$.

There is increasing evidence that exposure to coal combustion can affect respiratory health (21-25). In a study conducted in Poland, a highly significant $(P<0.05)$ reduction of $F E V_{1} / F V C$ values was observed among adult residents ( $\geq 40$ years old) who used coal for cooking or heating (26). A study conducted in a village of western India showed that the use of coal, together with other biomass fuels, was an important factor for pulmonary 
Table 1. Demographic and social characteristics, and values for pulmonary function measurements by coal exposure status.

\begin{tabular}{|c|c|c|c|}
\hline & Coal $(+)(n=110)$ & Coal $(-)(n=121)$ & $\mathrm{P}$ \\
\hline Age (year) & $43.7 \pm 12.5$ & $40.8 \pm 12.4$ & $=0.08$ \\
\hline Height (cm) & $163.7 \pm 6.6$ & $164.8 \pm 6.8$ & $=0.23$ \\
\hline Weight (kg) & $61.1 \pm 7.1$ & $62.6 \pm 7.5$ & $=0.16$ \\
\hline \multicolumn{4}{|l|}{ Gender } \\
\hline Male (\%) & 35.5 & 42.1 & $=0.30$ \\
\hline Female (\%) & 64.5 & 57.9 & \\
\hline Persons living in a home & $4.4 \pm 1.2$ & $4.1 \pm 1.3$ & $=0.06$ \\
\hline Number of rooms in a home & $3.9 \pm 1.2$ & $4.4 \pm 0.9$ & $<0.05$ \\
\hline History of recurrent pulmonary tract infections (\%) & 30.9 & 13.2 & $<0.05$ \\
\hline Environmental tobacco smoke exposure & 32.7 & 25.6 & $=0.23$ \\
\hline $\mathrm{FEV}_{1}(\mathrm{~L})$ & $2.75 \pm 0.56$ & $3.49 \pm 0.77$ & $<0.05$ \\
\hline $\mathrm{FVC}(\mathrm{L})$ & $3.22 \pm 0.62$ & $3.87 \pm 0.70$ & $<0.05$ \\
\hline $\mathrm{FEV}_{1} / \mathrm{FVC}(\%)$ & $83.13 \pm 3.95$ & $91.63 \pm 5.46$ & $<0.05$ \\
\hline $\operatorname{PEFR}(\mathrm{L} / \mathrm{s})$ & $6.00 \pm 0.90$ & $6.80 \pm 1.17$ & $<0.05$ \\
\hline $\mathrm{PM}_{2.5}$ relative concentration in kitchen $(\mathrm{cpm})$ & $569.5 \pm 50.1$ & $477.0 \pm 58.5$ & $<0.05$ \\
\hline $\mathrm{PM}_{2.5}$ relative concentration in living room (cpm) & $543.2 \pm 65.0$ & $452.7 \pm 51.2$ & $<0.05$ \\
\hline Outdoor $\mathrm{PM}_{2.5}$ relative concentration (cpm) & $416.2 \pm 5.9$ & $417.0 \pm 5.1$ & $=0.480$ \\
\hline
\end{tabular}

Data are reported as means $\pm S D$ or otherwise indicated. $\mathrm{P}$ values were determined with the independent-samples $t$-test for age, weight, height, persons in a home, number of rooms in a home, pulmonary function tests, and Pearson's chi-square test statistics for gender, history of recurrent pulmonary tract infections, and environmental tobacco smoke exposure. FEV i $_{1}$ forced expiratory volume in $1 \mathrm{~s}, \mathrm{FVC}$ : forced vital capacity, and PEFR: peak expiratory flow rate. Particulate matter had an aerodynamic diameter less than $2.5 \mathrm{~mm}$ $\left(\mathrm{PM}_{2.5}\right)$.

function deterioration. $\mathrm{FEV}_{1}(\mathrm{P}<0.05), \mathrm{FEV}_{1}$ percentage $(\mathrm{P}<0.01)$, PEFR $(\mathrm{P}<0.05)$, and forced expiratory flow between 25 and $75 \%\left(\mathrm{FEF}_{25-75}\right)$ values were significantly lower $(\mathrm{P}<0.01)$ in coal-using females than in non-users (21). There is consistent evidence (mainly from China), that exposure to coal smoke in the home markedly increases the risk of lung cancer, particularly in women
$(27,28)$. This deterioration of pulmonary function in coal users has been attributed to the amount and concentration of particulate matter and other toxic gases emitted during coal combustion. Similar to previous reports $(21,26)$, we observed highly significant reductions of FVC, FEV $1, F_{1} / F V C$, and PEFR in the exposed adults compared to individuals that used non-coal fuels.

Table 2. Estimated parameters and $95 \%$ confidence interval $(\mathrm{Cl})$ of multivariate linear regression analysis of forced vital capacity (FVC).

\begin{tabular}{lccc}
\hline Model components & Difference in FVC (L) & $95 \% \mathrm{Cl}$ & $\mathrm{P}$ \\
\hline Constant & 1.381 & $-1.930 ; 4.691$ & 0.409 \\
Coal (yes vs no) & -0.317 & $-0.396 ;-0.238$ & $<0.0001$ \\
Sex (male vs female) & 0.007 & $-0.053 ; 0.066$ & 0.826 \\
Age (per 1 year increase) & -0.033 & $-0.036 ;-0.030$ & $<0.0001$ \\
Height (per 1 cm increase) & -0.001 & $-0.005 ; 0.003$ & 0.694 \\
Weight (per 1 kg increase) & 0.030 & $0.016 ; 0.044$ & $<0.0001$ \\
Persons living in a home (per person more) & -0.017 & $-0.039 ; 0.005$ & 0.129 \\
Number of rooms in a home (per room more) & -0.006 & $-0.033 ; 0.020$ & 0.646 \\
History of recurrent respiratory tract infections (yes vs no) & -0.010 & $-0.077 ; 0.057$ & 0.767 \\
Environmental tobacco smoke exposure & -0.009 & $-0.073 ; 0.055$ & 0.778 \\
PM $_{2.5}$ relative concentration in kitchen (cpm) & -0.002 & $-0.004 ; 0.000$ & $<0.05$ \\
PM $_{2.5}$ relative concentration in living room (cpm) & 0.001 & $-0.001 ; 0.002$ & 0.519 \\
Outdoor PM $_{2.5}$ relative concentration (cpm) & 0.000 & $-0.006 ; 0.005$ & 0.890 \\
\hline
\end{tabular}

Reference categories are non-coal exposure, females, no history of recurrent respiratory tract infections, and no tobacco smoke exposure. 
Table 3. Estimated parameters and $95 \%$ confidence interval $(\mathrm{Cl})$ of multivariate linear regression analysis of forced expiratory volume $\left(\mathrm{FEV}_{1}\right)$ in $1 \mathrm{~s}$.

\begin{tabular}{lccc}
\hline Model components & Difference in FEV $(\mathrm{L})$ & $95 \% \mathrm{Cl}$ & $\mathrm{P}$ \\
\hline Constant & -12.700 & $-17.047 ;-8.352$ & $<0.0001$ \\
Coal (yes vs no) & -0.420 & $-0.525 ;-0.316$ & $<0.0001$ \\
Sex (male vs female) & 0.037 & $-0.041 ; 0.115$ & 0.348 \\
Age (per 1 year increase) & -0.026 & $-0.030 ;-0.022$ & $<0.0001$ \\
Height (per 1 cm increase) & 0.003 & $-0.002 ; 0.009$ & 0.229 \\
Weight (per 1 kg increase) & 0.090 & $0.072 ; 0.109$ & $<0.0001$ \\
Persons living in a home (per person more) & -0.020 & $-0.049 ; 0.009$ & 0.169 \\
Number of rooms in a home (per room more) & -0.013 & $-0.048 ; 0.021$ & 0.446 \\
History of recurrent respiratory tract infections (yes vs no) & 0.000 & $-0.089 ; 0.088$ & 0.991 \\
Environmental tobacco smoke exposure & -0.003 & $-0.086 ; 0.081$ & 0.950 \\
PM $_{2.5}$ relative concentration in kitchen (cpm) & -0.003 & $-0.005 ; 0.000$ & $<0.05$ \\
PM $_{2.5}$ relative concentration in living room (cpm) & 0.006 & $-0.004 ; 0.008$ & 0.561 \\
Outdoor PM $_{2.5}$ relative concentration (cpm) & 0.002 & $-0.005 ; 0.008$ & 0.658 \\
\hline
\end{tabular}

Reference categories are non-coal exposure, females, no history of recurrent respiratory tract infections, and no tobacco smoke exposure.

Adults exposed to IAP from coal combustion have also been found to have decreased pulmonary function, often associated with chronic obstructive lung disease (26). Given the high proportion of reported recurrent respiratory tract infections and the lower values of some pulmonary function test parameters (e.g., FVC, FEV $1, F_{1} V_{1} / F V C$, and PEFR) that are associated with a higher risk for obstructive lung diseases, we speculate that the risk of chronic obstructive lung disease may be increased among the coal users in our study.

Because the weather is usually cold and cloudy during winter in Zunyi, and also because the Zunyi district has rich deposits of coal, it is natural that there is a large demand for coal, which is used for heating and cooking in winter. Therefore, coal is the major domestic fuel for most households. Most of the coal used by Zunyi households is a high-sulfur coal with a sulfur content of approximately $3 \%$ (13). For many people, the risks to respiratory health may be greater due to exposure to excessively high indoor air pollutants from poorly ventilated household stoves.

Observational studies $(4,6,14)$ that have evaluated the adverse pulmonary health effects of indoor solid fuel (prevalence of respiratory diseases and related symptoms or changes in pulmonary function) used qualitative assessments of exposure, such as fuel type or urban vs rural. Few of those studies also investigated the exposure

Table 4. Estimated parameters and $95 \%$ confidence interval $(\mathrm{Cl})$ of multivariate linear regression analysis of $\mathrm{FEV} / / \mathrm{FVC}$ ratio.

\begin{tabular}{lccc}
\hline Model components & $\begin{array}{c}\text { Difference in } \\
\text { FEV }_{1} / \mathrm{FVC}(\%)\end{array}$ & $95 \% \mathrm{Cl}$ & \\
\hline Constant & 3.563 & $-93.878 ; 101.003$ & 0.942 \\
Coal (yes vs no) & -7.463 & $-9.797 ;-5.129$ & $<0.0001$ \\
Sex (male vs female) & 1.138 & $-0.603 ; 2.880$ & 0.198 \\
Age (per 1 year increase) & 0.012 & $-0.076 ; 0.100$ & 0.785 \\
Height (per 1 cm increase) & 0.024 & $-0.098 ; 0.145$ & 0.696 \\
Weight (per 1 kg increase) & 0.398 & $-0.011 ; 0.808$ & 0.056 \\
Persons living in a home (per person more) & 0.444 & $-0.205 ; 1.093$ & 0.177 \\
Number of rooms in a home (per room more) & -0.100 & $-0.877 ; 0.678$ & 0.799 \\
History of recurrent respiratory tract infections (yes vs no) & 0.555 & $-1.418 ; 2.528$ & 0.578 \\
Environmental tobacco smoke exposure & 0.965 & $-0.912 ; 2.842$ & 0.310 \\
PM ${ }_{2.5}$ relative concentration in kitchen (cpm) & 0.008 & $-0.044 ; 0.060$ & 0.757 \\
PM $_{2.5}$ relative concentration in living room (cpm) & -0.002 & $-0.050 ; 0.046$ & 0.924 \\
Outdoor PM $_{2.5}$ relative concentration (cpm) & 0.036 & $-0.116 ; 0.188$ & 0.638 \\
\hline
\end{tabular}

Reference categories are non-coal exposure, females, no history of recurrent respiratory tract infections, and no tobacco smoke exposure. 
Table 5. Estimated parameters and $95 \%$ confidence interval $(\mathrm{Cl})$ of multivariate linear regression analysis of peak expiratory flow rate (PEFR; L/min).

\begin{tabular}{|c|c|c|c|}
\hline Model components & Difference in PEFR (L/s) & $95 \% \mathrm{Cl}$ & $\mathrm{P}$ \\
\hline Constant & 8.774 & $-0.780 ; 18.327$ & 0.071 \\
\hline Coal (yes vs no) & -0.231 & $-0.460 ;-0.002$ & $<0.05$ \\
\hline Sex (male vs female) & 0.006 & $-0.165 ; 0.176$ & 0.948 \\
\hline Age (per 1 year increase) & -0.053 & $-0.061 ;-0.044$ & $<0.0001$ \\
\hline Height (per $1 \mathrm{~cm}$ increase) & 0.003 & $-0.009 ; 0.015$ & 0.573 \\
\hline Weight (per 1 kg increase) & 0.005 & $-0.035 ; 0.045$ & 0.798 \\
\hline Persons living in a home (per person more) & 0.024 & $-0.040 ; 0.087$ & 0.459 \\
\hline Number of rooms in a home (per room more) & 0.000 & $-0.076 ; 0.076$ & 0.995 \\
\hline History of recurrent respiratory tract infections (yes vs no) & 0.075 & $-0.118 ; 0.269$ & 0.441 \\
\hline Environmental tobacco smoke exposure & 0.004 & $-0.180 ; 0.188$ & 0.964 \\
\hline $\mathrm{PM}_{2.5}$ relative concentration in kitchen $(\mathrm{cpm})$ & -0.008 & $-0.013 ;-0.003$ & $<0.05$ \\
\hline $\mathrm{PM}_{2.5}$ relative concentration in living room (cpm) & 0.002 & $-0.003 ; 0.006$ & 0.515 \\
\hline Outdoor $\mathrm{PM}_{2.5}$ relative concentration $(\mathrm{cpm})$ & 0.007 & $-0.009 ; 0.020$ & 0.466 \\
\hline
\end{tabular}

Reference categories are non-coal exposure, females, no history of recurrent respiratory tract infections, and no tobacco smoke exposure.

levels of particulate matter less than $10 \mathrm{~mm}$ in diameter (29). No study has yet evaluated all of these effects in the same population and also considered the intensity of exposure to $\mathrm{PM}_{2.5}$. Pollutants from indoor coal combustion are a complicated mixture of aerosol and gases such as particulate matter, $\mathrm{SO}_{2}, \mathrm{CO}$, and others (6). Our study confirmed high concentrations of $\mathrm{PM}_{2.5}$ in the kitchen and adjacent living area. The relative concentrations of $\mathrm{PM}_{2.5}$ in the kitchen and living room during coal combustion were significantly higher than during non-coal combustion, and linear regression analysis revealed that the $\mathrm{PM}_{2.5}$ relative concentration in the kitchen was inversely correlated with pulmonary function test data, which suggests that coal fuel combustion might have contributed to impaired lung function among adult individuals.

In this study, we made an effort to determine the effects of coal use on pulmonary function by adjusting for confounding factors as much as possible. These adjustments were extremely important in such a study because the confounding effects of different factors have been reported to be responsible for some conflicting findings (30). We used multivariate analysis in the present study to control for the effects of gender, age, height, weight, number of persons living in a home, number of rooms in a home, history of recurrent respiratory tract infections, environmental tobacco smoke exposure, and $\mathrm{PM}_{2.5}$ relative concentration in the kitchen, living room, and outdoors.

Several limitations of the present study need to be

\section{References}

1. Baumgartner J, Schauer JJ, Ezzati M, Lu L, Cheng C, Patz $\mathrm{J}$, et al. Patterns and predictors of personal exposure to indoor air pollution from biomass combustion among women acknowledged. First, the sample size was relatively small. Second, when interpreting the results of this study, it is important to note that the cross-sectional design limited causal inference. For example, past exposure to coal smoke and recent changes in coal use were not assessed. Third, we cannot comment on the duration of exposure to coal smoke because we could not adequately assess cooking times in households. Furthermore, other factors such as living in a different location, socioeconomic status, and outdoor air pollution could have biased our results. Despite these limitations, our study provides an overview of the relationship of pulmonary function changes to IAP from coal use among adult residents in inner-city areas of southwest China.

Prospective studies are needed to assess the longterm effects of coal smoke on lung health among adults. Given the extensive use of coal fuel, public health efforts concerned with respiratory health in the developing world, particularly in China, should address the risks of IAP exposure.

\section{Acknowledgments}

Research supported by the National Natural Science Foundation of China (\#81360419) and the Key Technologies R\&D Programme of the Department of Science and Technology of Guizhou Province, China (\#SY[2011]3029, \#SY[2012]3126, and \#SY[2013]3027). and children in rural China. Indoor Air 2011; 21: 479-488, doi: 10.1111/j.1600-0668.2011.00730.x.

2. Yu Jie, Huang Houjin, Jin Feng, Xu Jie. The role of airborne 
microbes in school and its impact on asthma, allergy and respiratory symptoms among school children. Rev Med Microbiol 2011; 22: 84-89, doi: 10.1097/MRM.0b013e 32834a449c.

3. Ho LA, Kuschner WG. Respiratory health in home and leisure pursuits. Clin Chest Med 2012; 33: 715-729, doi: 10.1016/j.ccm.2012.08.001.

4. Jie $\mathrm{Y}$, Isa ZM, Jie $\mathrm{X}$, Ju ZL, Ismail NH. Urban vs. rural factors that affect adult asthma. Rev Environ Contam Toxicol 2013; 226: 33-63.

5. Diaz-Guzman E, Mannino DM. Epidemiology and prevalence of chronic obstructive pulmonary disease. Clin Chest Med 2014; 35: 7-16, doi: 10.1016/j.ccm.2013.10.002.

6. Jie $\mathrm{Y}$, Ismail $\mathrm{NH}$, Jie $\mathrm{X}$, Isa ZM. Do indoor environments influence asthma and asthma-related symptoms among adults in homes?: a review of the literature. J Formos Med Assoc 2011; 110: 555-563, doi: 10.1016/j.jfma.2011.07.003.

7. Scaccia S, Mecozzi R. Trace $\mathrm{Cd}$, Co, and Pb elements distribution during Sulcis coal pyrolysis: GFAAS determination with slurry sampling technique. Microchem J 2012; 100: 48-54, doi: 10.1016/j.microc.2011.09.001.

8. Jiang $\mathrm{R}$, Bell ML. A comparison of particulate matter from biomass-burning rural and non-biomass-burning urban households in northeastern China. Environ Health Perspect 2008; 116: 907-914, doi: 10.1289/ehp.10622.

9. Madrigano J, Kloog I, Goldberg R, Coull BA, Mittleman MA, Schwartz J. Long-term exposure to $\mathrm{PM}_{2.5}$ and incidence of acute myocardial infarction. Environ Health Perspect 2013; 121: 192-196.

10. da Silva LF, Saldiva SR, Saldiva PH, Dolhnikoff M. Impaired lung function in individuals chronically exposed to biomass combustion. Environ Res 2012; 112: 111-117, doi: 10.1016/ j.envres.2011.10.012.

11. Jie $Y$, Houjin $H$, Mengxue $Y$, Wei $Q$, Jie $X$. A time series analysis of meteorological factors and hospital outpatient admissions for cardiovascular disease in the Northern district of Guizhou Province, China. Braz J Med Biol Res 2014; 47: 689-696, doi: 10.1590/1414-431X2014424.

12. Yu J, Zhang LJ, Liu XL, Jin H, Xu J. The impact of ambient temperature on pulmonary morbidity among the urban population in Zunyi, China. Pol J Environ Stud 2013; 22: 717-726.

13. Zunyi Municipal People's Government. Zunyi Clean Energy Plan Report 1995-2000. Zunyi: Municipal People's Government; 2002.

14. Yu Jie, Zaleha Md Isa, Xu Jie, Noor Hassim Ismail. Asthma and asthma-related symptoms among adults of an acid rainplagued city in Southwest China: Prevalence and risk factors. Pol J Environ Stud 2013; 22: 717-726.

15. Ruppel GL, Enright PL. Pulmonary function testing. Respir Care 2012; 57: 165-175, doi: 10.4187/respcare.01640.

16. Miller MR, Hankinson J, Brusasco V, Burgos F, Casaburi R, Coates A, et al. Standardisation of spirometry. Eur Respir J 2005; 26: 319-338, doi: 10.1183/09031936.05.00034805.

17. Sibata. Dust measurement and Sibata products. http://www. sibata.co.jp/english/product_data/pdf/Dust\%20Measurement $\% 20$ and $\% 20$ SIBATA\%20Products.pdf. Accessed September 18, 2012.
18. Leroyer C, Perfetti L, Trudeau C, L'Archevěque J, ChanYeung M, Malo JL. Comparison of serial monitoring of peak expiratory flow and $\mathrm{FEV}_{1}$ in the diagnosis of occupational asthma. Am J Respir Crit Care Med 1998; 158: 827-832, doi: 10.1164/ajrccm.158.3.9707093.

19. Lan Q, Mumford JL, Shen M, Demarini DM, Bonner MR, He $X$, et al. Oxidative damage-related genes AKR1C3 and OGG1 modulate risks for lung cancer due to exposure to $\mathrm{PAH}$-rich coal combustion emissions. Carcinogenesis 2004; 25: 2177-2181, doi: 10.1093/carcin/bgh240.

20. Padhy PK, Padhi BK. Effects of biomass combustion smoke on hematological and antioxidant profile among children (813 years) in India. Inhal Toxicol 2009; 21: 705-711, doi: 10.1080/08958370802448961.

21. Saha A, Rao NM, Kulkarni PK, Majumdar PK, Saiyed HN. Pulmonary function and fuel use: a population survey. Respir Res 2005; 6: 127, doi: 10.1186/1465-9921-6-127.

22. Qian Z, He Q, Kong L, Xu F, Wei F, Chapman RS, et al. Respiratory responses to diverse indoor combustion air pollution sources. Indoor Air 2007; 17: 135-142, doi: 10.1111/j.1600-0668.2006.00463.x.

23. Barry AC, Mannino DM, Hopenhayn C, Bush H. Exposure to indoor biomass fuel pollutants and asthma prevalence in Southeastern Kentucky: results from the Burden of Lung Disease (BOLD) study. J Asthma 2010; 47: 735-741, doi: 10.3109/02770903.2010.485661.

24. Shimada $\mathrm{Y}$, Matsuoka $\mathrm{Y}$. Analysis of indoor $\mathrm{PM}_{2.5}$ exposure in Asian countries using time use survey. Sci Total Environ 2011; 409: 5243-5252, doi: 10.1016/j.scitotenv.2011. 08.041 .

25. Diette GB, Accinelli RA, Balmes JR, Buist AS, Checkley W, Garbe $P$, et al. Obstructive lung disease and exposure to burning biomass fuel in the indoor environment. Glob Heart 2012; 7: 265-270, doi: 10.1016/j.gheart.2012.06.016.

26. Mejza F, Nastalek P, Skucha W, Harat R, NizankowskaMogilnicka E. [Effects of biomass combustion and occupational exposures on lung function in random population sample of Malopolska inhabitants]. Pneumonol Alergol Pol 2012; 80: 509-515.

27. Shen M, Chapman RS, Vermeulen R, Tian L, Zheng T, Chen $\mathrm{BE}$, et al. Coal use, stove improvement, and adult pneumonia mortality in Xuanwei, China: a retrospective cohort study. Environ Health Perspect 2009; 117: 261-266, doi: 10.1289/ehp.11521.

28. Barone-Adesi F, Chapman RS, Silverman DT, He X, Hu W, Vermeulen $R$, et al. Risk of lung cancer associated with domestic use of coal in Xuanwei, China: retrospective cohort study. BMJ 2012; 345: e5414, doi: 10.1136/ bmj.e5414.

29. Liu S, Zhou Y, Wang X, Wang D, Lu J, Zheng J, et al. Biomass fuels are the probable risk factor for chronic obstructive pulmonary disease in rural South China. Thorax 2007; 62: 889-897, doi: 10.1136/thx.2006.061457.

30. Fullerton DG, Suseno A, Semple S, Kalambo F, Malamba $\mathrm{R}$, White $\mathrm{S}$, et al. Wood smoke exposure, poverty and impaired lung function in Malawian adults. Int $J$ Tuberc Lung Dis 2011; 15: 391-398. 